\title{
Diabetic papillopathy with macular edema treated with intravitreal ranibizumab
}

\author{
Moosang Kim* \\ Jang-Hun Lee* \\ Seung-Jun Lee \\ Department of Ophthalmology, \\ Kangwon National University, \\ Chuncheon, South Korea \\ *These authors contributed equally to \\ this work
}

Correspondence: Seung-Jun Lee Department of Ophthalmology, Kangwon National University Hospital, I56 Baengnyeong-ro, Chuncheon, Gangwon 200-722, South Korea Tel +82 332582014

Fax +82 29667340

Email ophkimmoo@gmail.com
This article was published in the following Dove Press journal:

Clinical Ophthalmology

26 November 2013

Number of times this article has been viewed
Abstract: We report a case of diabetic papillopathy that demonstrated a resolution of optic disk swelling and rapid visual recovery when intravitreal ranibizumab was administered. A 51-year-old male presented with acute painless visual loss in his right eye. His vision was 20/320 in the right eye and 20/50 in the left eye. Fundus examination of the right eye showed nonproliferative diabetic retinopathy with macular edema and a swollen optic disk. Fluorescein angiography showed dye leakage from the right optic disk. Optical coherent tomography revealed a significant increase in retinal nerve fiber-layer thickness. Magnetic resonance imaging of the brain was normal. The patient received a single intravitreal ranibizumab $(0.5 \mathrm{mg})$ injection. Two weeks following injection, there was marked regression of the disk swelling and improvement of macular edema, with vision improving to 20/100. Three months following injection, there was complete resolution of the optic disk swelling. No further treatment was required.

Keywords: diabetic papillopathy, optic disk swelling, ranibizumab

\section{Introduction}

Diabetic papillopathy (DP) is a syndrome characterized by self-limited unilateral or bilateral optic disk swelling associated with minimal or no permanent loss of visual function. ${ }^{1-3}$ DP may occur in patients with type 1 diabetes mellitus (DM) ${ }^{1}$ and type 2 $\mathrm{DM},{ }^{2,3}$ with approximately a $0.5 \%$ incidence, ${ }^{1}$ irrespective of metabolic control and severity of diabetic retinopathy. DP is a diagnosis of exclusion, made after other causes of disk swelling have been ruled out. Likely ischemic in origin, DP is considered by some authors to be a form of ischemic optic neuropathy. ${ }^{4}$ The etiology of DP is not well understood, and there is no accepted treatment to alter its natural course. In recent case reports, treatment with a single injection of intravitreal triamcinolone acetate or intravitreal inhibitor of vascular endothelial growth factor (VEGF) was effective in reducing disk swelling. ${ }^{5-9}$ However, only one report was found in a literature search that was performed with intravitreal ranibizumab (Lucentis ${ }^{\circledR}$; Novartis, Basel, Switzerland) injection. ${ }^{9}$ We report a second case of DP that demonstrated resolution of optic disk swelling and rapid visual recovery when intravitreal ranibizumab was administered.

\section{Case report}

A 51-year-old male with a 10-year history of poorly controlled type 2 DM presented with acute painless visual loss in his right eye. His best-corrected visual acuity was 20/320 in the right eye and 20/50 in the left eye. Intraocular pressure was $12 \mathrm{mmHg}$ in both eyes. An anterior-segment examination showed moderate nuclear sclerosis of both lenses. There was no afferent pupillary defect. Fundus examination of the 
right eye showed nonproliferative diabetic retinopathy with serous retinal detachment and a swollen optic disk with telangiectatic vessels (Figure 1A). Fluorescein angiography of the right eye showed optic disk leakage with the presence of microaneurysm (Figure 1B). Optical coherent tomography imaging of the right eye revealed serous macular detachment and a significant increase in retinal nerve fiber-layer thickness (Figure 1C and D). Visual field examination showed diffuse depression on the right eye. Pattern visual evoked potential showed normal findings. The patient underwent clinical neurologic examination (including brain magnetic resonance imaging), blood pressure measurement, and complete blood count and electrolyte testing, all of which were within normal limits. Glycosylated hemoglobin was $10.9 \%$. A diagnosis of DP and diabetic macular edema in the right eye was made. DP is a diagnosis of exclusion, made after other causes of disk swelling have been ruled out. Through full explanation of the expected effects and possible complications of intravitreal ranibizumab injection, informed consent was obtained from the patient before injection, and intravitreal ranibizumab $(0.5 \mathrm{mg} / 0.05 \mathrm{~mL})$ injection was performed using the standard technique.

Two weeks following injection, there was marked regression of disk swelling and improvement of macular edema, with visual acuity improving to 20/100 (Figure 2A and B). Three months following injection, there was complete resolution of optic disk swelling, and visual acuity was 20/50 in his right eye (Figure $3 \mathrm{~A}$ and B). No further treatment was required.

\section{Discussion}

Many pathological conditions may mimic DP, such as inflammation (eg, sarcoidosis), infection (eg, Lyme disease), cancerous infiltration (eg, leukemia), hypertension, papilledema, and disk ischemia. ${ }^{1,3,10} \mathrm{~A}$ diagnosis of DP was made due to the following reasons: uncontrolled type 2 DM, painless visual loss, presence of associated macular edema, which is common in DP, ${ }^{1}$ early disk hyperfluorescence on fluorescein angiography, and good visual outcome posttreatment.

Recently, intravitreal injection of anti-VEGF was reported to be associated with visual improvement and reduced optic disk swelling without adverse events in patients with DP. ${ }^{7-9}$ However, the mechanism of action of anti-VEGF (such as bevacizumab or ranibizumab) in patients with DP is not well understood. The good response to the treatment may suggest that VEGF plays an important role in the pathogenesis of DP. In the present case, DP had largely resolved 2 weeks after intravitreal ranibizumab injection, while vision had improved from 20/320 to 20/100. The spontaneous course of DP tends to be more protracted, with regression of the disk edema occurring over months and visual recovery often being incomplete. ${ }^{11} \mathrm{DP}$ had not reappeared in our patient at

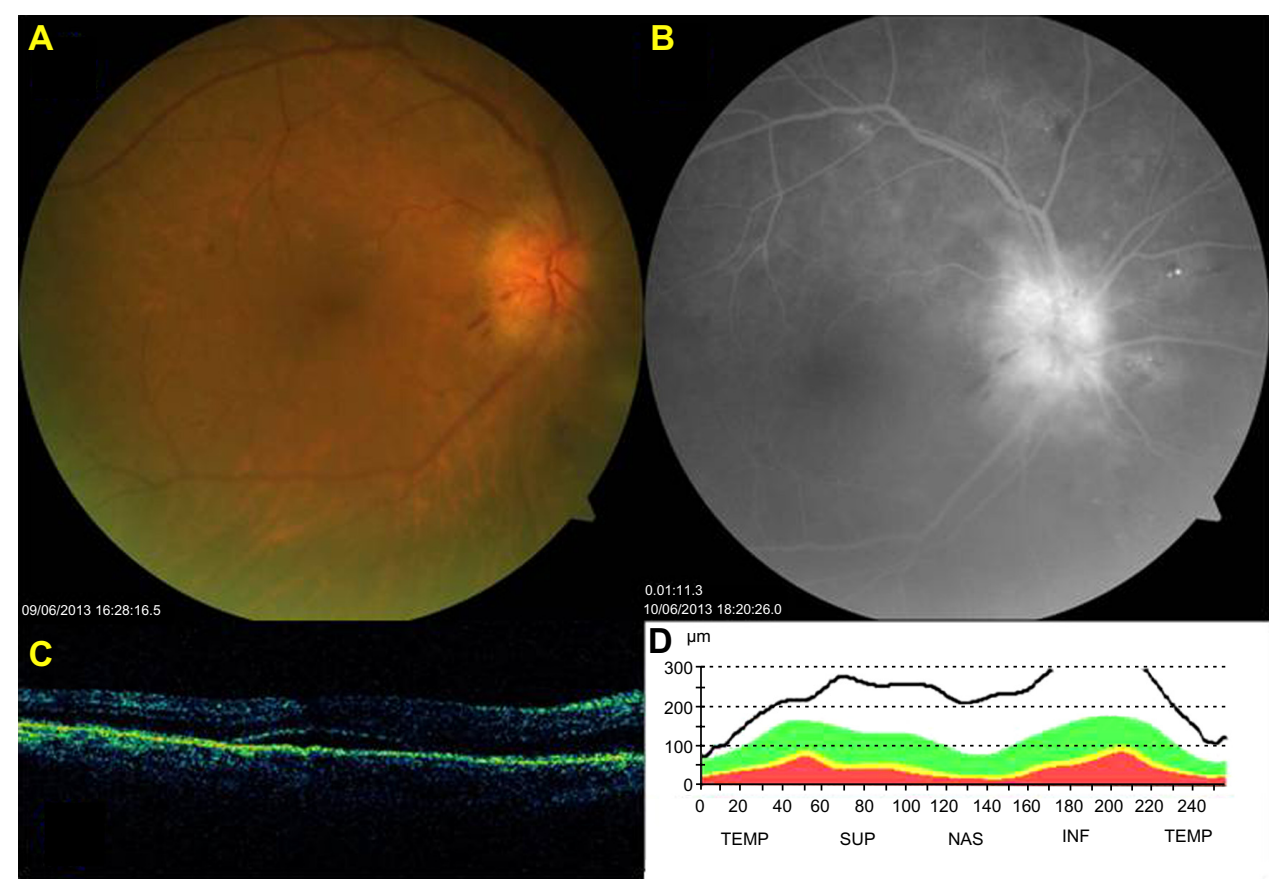

Figure I (A-D) At presentation. (A) Fundus photography showing swollen optic disk. (B) Fluorescein angiography showing disk-vessel telangiectasia and disc leakage. (C and D) Optical coherence tomography scan showing a serous macular detachment. Marked edema of the optic disk and thickening of the retinal nerve-fiber layer. Abbreviations: TEMP, temporal; SUP, superior; NAS, nasal; INF, inferior. 


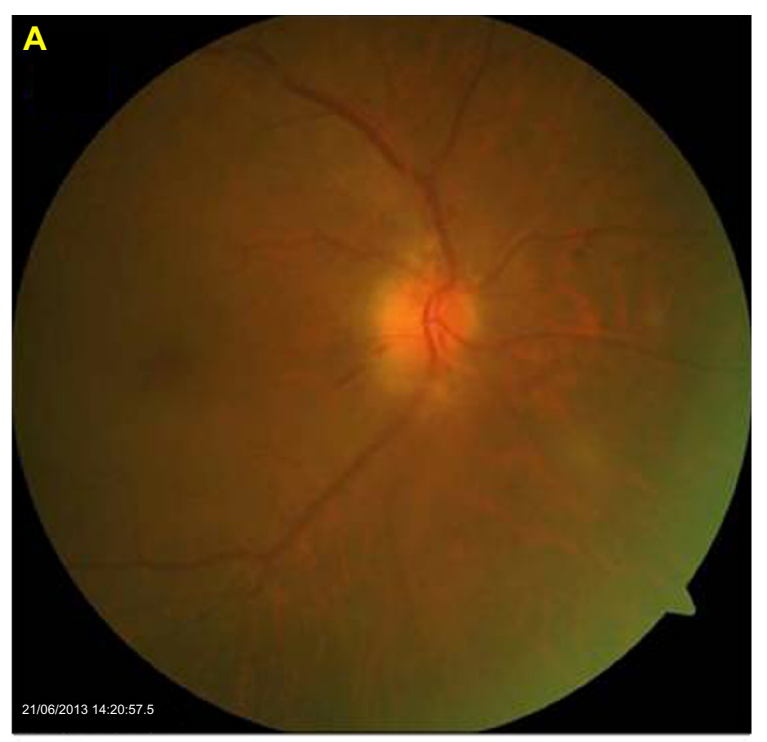

B $\mu \mathrm{m}$

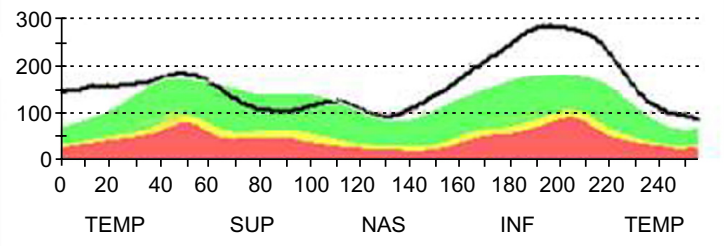

Figure 2 (A and $\mathbf{B}$ ) Two weeks postinjection. (A and B) Fundus photography showing marked regression of disk swelling.

Abbreviations: TEMP, temporal; SUP, superior; NAS, nasal; INF, inferior.

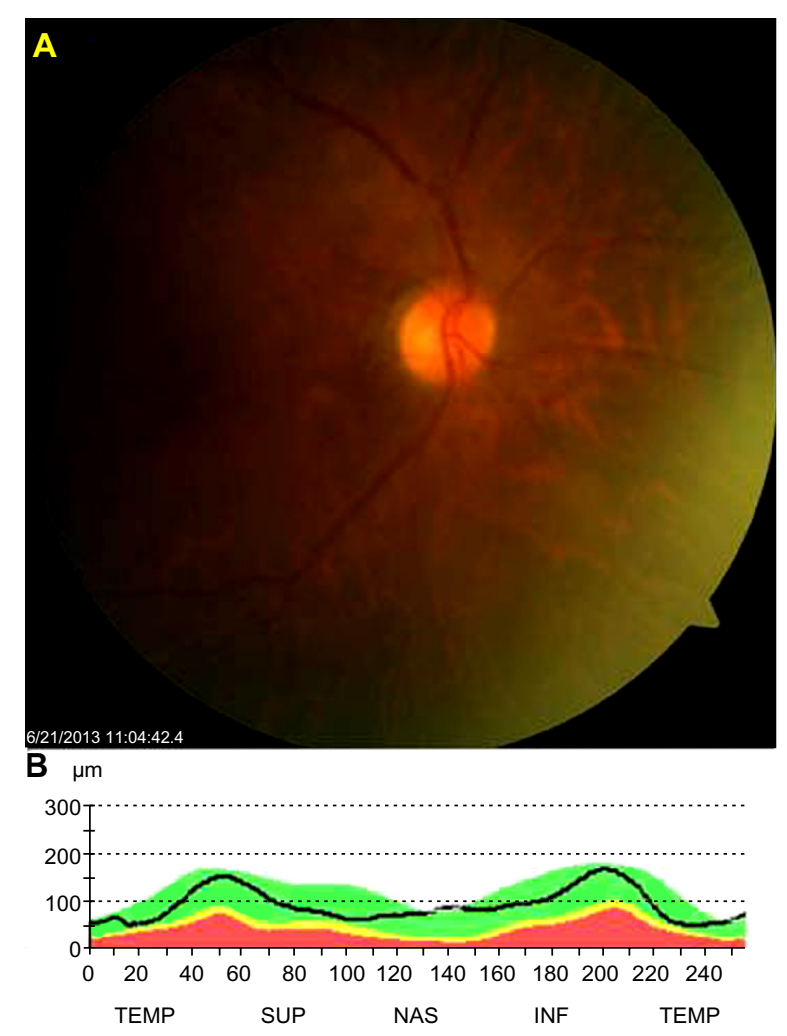

Figure 3 (A and $\mathbf{B}$ ) Three months postinjection. (A and $\mathbf{B}$ ) Fundus photography showing complete resolution of optic disk swelling.

Abbreviations: TEMP, temporal; SUP, superior; NAS, nasal; INF, inferior. the 3-month follow-up, which is three times longer than the effective duration of VEGF inhibition after a single ranibizumab injection.

\section{Conclusion}

A rapid improvement in vision was noted in our patient shortly after intravitreal injection of ranibizumab. Therefore, it may be that the intravitreal ranibizumab played a positive role in stabilizing and improving the patient's optic nerve edema. However, the efficacy and safety of this management of DP needs to be proven through further larger clinical studies.

\section{Disclosure}

The authors report no conflicts of interest in this work.

\section{References}

1. Regillo CD, Brown GC, Savino PJ, et al. Diabetic papillopathy: patient characteristics and fundus findings. Arch Ophthalmol. 1995;113(7): 889-895.

2. Friedrich Y, Feiner M, Gawi H, Friedman Z. Diabetic papillopathy with macular star mimicking clinically significant macular edema. Retina. 2001;21(1):80-82.

3. Bayraktar Z, Alacali N, Bayraktar S. Diabetic papillopathy in type II diabetic patients. Retina. 2002;22(6):752-758.

4. Hayreh SS, Zimmerman B. Nonarteritic anterior ischemic optic neuropathy: clinical characteristics in diabetic patients versus nondiabetic patients. Ophthalmology. 2008;115(10):1818-1825.

5. Mansour AM, El-Dairi MA, Shehab MA, Shahin HK, Shaaban JA, Antonios SR. Periocular corticosteroids in diabetic papillopathy. Eye (Lond). 2005;19(1):45-51.

6. Al-Haddad CE, Jurdi FA, Bashshur ZF. Intravitreal triamcinolone acetonide for the management of diabetic papillopathy. Am J Ophthalmol. 2004;137(6):1151-1153.

7. Al-Hinai AS, Al-Abri MS, Al-Hajri RH. Diabetic papillopathy with macular edema treated with intravitreal bevacizumab. Oman $J$ Ophthalmol. 2011;4(3):135-138.

8. Al-Dhibi H, Khan AO. Response of diabetic papillopathy to intravitreal bevacizumab. Middle East Afr J Ophthalmol. 2011;18(3):243-245.

9. Willerslev A, Munch IC, Larsen M. Resolution of diabetic papillopathy after a single intravitreal injection of ranibizumab. Acta Ophthalmol. 2012;90(5):e407-e409.

10. Katz B. Disc swelling in an adult diabetic patient. Surv Ophthalmol. 1990;35(2):158-163.

11. Ostri C, Lund-Andersen H, Sander B, Hvidt-Nielsen D, Larsen M. Bilateral diabetic papillopathy and metabolic control. Ophthalmology. 2010;117(11):2214-2217. 


\section{Publish your work in this journal}

Clinical Ophthalmology is an international, peer-reviewed journal covering all subspecialties within ophthalmology. Key topics include: Optometry; Visual science; Pharmacology and drug therapy in eye diseases; Basic Sciences; Primary and Secondary eye care; Patient Safety and Quality of Care Improvements. This journal is indexed on
PubMed Central and CAS, and is the official journal of The Society of Clinical Ophthalmology (SCO). The manuscript management system is completely online and includes a very quick and fair peer-review system, which is all easy to use. Visit http://www.dovepress.com/ testimonials.php to read real quotes from published authors. 